\title{
Del decir y lo dicho (otra vuelta de tuerca)
}

\author{
Francisco Javier Gómez Tarín \\ Universitat Jaume I
}

RUBIO ALCOVER, Agustín (2010).

El don de la imagen. Un concepto del cine contemporáneo.

Volumen I: Esperantistas.

Santander: Shangrila Ediciones.

Después de las múltiples ediciones de textos más o menos relevantes sobre el cine contemporáneo y esa pléyade de libros, artículos y demás que ocultan sus limitaciones bajo el sombrero-aparcamiento y cubre-lluvias de la etiqueta postmoderna (allá donde el "todo vale" campa a sus anchas), podría parecer, a primera y miope vista, que el volumen escrito por Agustín Rubio es uno más y que poco puede aportar a tantísima gama de posibilidades (para todos los gustos o, mejor, Le goût des autres). Nada más lejos de la realidad -de la nuestra, al menos de quien escribe estas líneas-, toda vez que siembra y recoge los frutos de un saber múltiple: un saber engendrado por el conocimiento, un saber aplicado a la reflexión, un saber orientado hacia la discusión y, lo más importante, un saber cargado en/por la batería de la provocación (¿ajuste de cuentas?).

Comenzaré, si se me permite, por esta última cuestión, la de la provocación, explicando por qué me refiero a un posible ajuste de cuentas. El don de la imagen es un libro a leer con fruición - de eso nos ocuparemos más adelante-, pero es también un libro que abre otros usos a los que no quiero sustraerme: los del ajuste de cuentas no solamente con una muy habitual visión chata del cine, en su vía historiográfica, sino también con una más que cierta concepción aberrante, hoy dominante, del valor investigador que se autojustifica por una supuesta dimensión empirista plasmada en plantillas y datos. Ciertamente, los tiempos que corren imponen carreras curriculares -al menos en el mundo de la docencia- basadas en criterios de calidad establecidos a partir de parámetros de indexación en revistas que se establecen como pauta y norte (huelga decir el cúmulo de despropósitos que rige esta cualificación y los intereses creados 
que la rodean hasta estrangular las posibilidades de los aspirantes a "medalla"). Considerar el territorio de las Humanidades o de las Ciencias Sociales con criterios similares a los de las Ciencias Exactas (que, de hecho, poco tienen de tales, ya que, a fin de cuentas, todo son relatos y de ese bucle es poco menos que imposible deshacerse) tiene poca justificación, pero es un hecho que el poder impone sus criterios y ajusta sus ventajas para mantenerlas de por vida. La consecuencia no es otra que la multiplicación hasta la extenuación de textos que siguen unas pautas similares (a modo de aplicaciones de plantilla), una estructura idéntica y, sobre todo, una acumulación de datos, datos y más datos... es necesario ser "empíricos". El lector avispado habrá comprendido inmediatamente que ese empirismo es de salón y los textos son calcos unos de otros, resúmenes de resúmenes, y repeticiones hasta el infinito de la mediocridad cuando no de la nadería. Así nos va.

Pues bien, el libro que aquí reseñamos se caracteriza preci(o)samente por una carga de profundidad que se manifiesta en su mismo significante, en su exterioridad: la apuesta inequívoca por una visión/concepción personal que huye de evocar aquello que otros han dicho antes, o la historia que se ha escrito, o las citas de una supuesta autoridad, para plasmar en sus casi quinientas páginas una idea de cine, una idea propia, con todo lo que pueda tener de discutible o de asumible para el lector, íntima e irreductible. De ahí que podamos hacer uso de su falta de empirismo para reivindicar eso precisamente: el abandono del empirismo y la asunción de la subjetividad, del ensayo, como la forma que aporta un más profundo conocimiento de las cosas por su transferencia de lo personal a lo universal. Cuando las reflexiones que llegan al lector tienen la fuerza expositiva de que hace gala Agustín Rubio, provocan el debate (aunque este sea interno) y re-reflexión (sí, son dos "res") sobre las ideas previas concebidas o perpetradas por enunciaciones previas amparadas en el cajón de sastre del consabido empirismo, aquí abandonado felizmente.

A la vista está, el libro me ha dado pie para lanzar una diatriba contra la concepción empírica de la ciencia (al menos en este lado social en que nos movemos), porque no puede negarse su vinculación al ambiente docente en que el autor, profesor de universidad, ejerce. Y este es otro gran mérito, porque se aleja de los usos y costumbres hegemónicos para disponer el texto de tal forma que no sigue cánones. El otro canon, el historiográfico, no condiciona El don de la imagen tampoco: movimientos, fechas, escuelas, películas... aparecen y desaparecen en un orden que se adapta a esa idea de cine que rige en todo el relato (relato, sí, así lo reivindico, y lo hago con un contenido semántico absolutamente positivo... relato que se sabe relato)

La lectura del libro establece un diálogo permanente entre autor y lector, una relación dialéctica que contribuye a la discusión íntima sobre las concepciones previas que cada cual tiene sobre esta o aquella película, sobre éste o aquel movimiento cinematográfico. No están todos/as los que son, pero sí son todos/ as los/as que están. Y es bueno que así sea porque el ejercicio que lleva a cabo 
Agustín Rubio le permite navegar por el proceloso mar de la historia del cine saltando entre islotes, ora asumiendo la revisitación de algunos, ora dejando de lado otros. No hay aquí una historia del cine, pero sí una historia de una idea de cine, esa que Deleuze reivindicó y que tanto brilla por su ausencia en las publicaciones al uso.

He dejado para el final otra de las características esenciales de El don de la imagen: la calidad de la escritura, que da contenido al título de esta reseña. No solamente lo dicho es importante y los análisis brillantes, sino que el decir es el vehículo más adecuado para ello, un decir propio de escritor y no de científico. ¡Por fin, un texto en el que el decir y lo dicho se fusionan como el significante y el significado, como el espacio y el tiempo, como el cuerpo y el alma... de eso están hechas las palabras (y la vida), no de datos!.

\section{Referencia de este artículo}

Gómez Tarín, Francisco Javier (2011). Del decir y lo dicho (otra vuelta de tuerca). En: adComunica. Revista Científica de Estrategias, Tendencias e Innovación en Comunicación, $\mathrm{n}^{0}$ 1. Castellón: Asociación para el Desarrollo de la Comunicación adComunica, Universidad Complutense de Madrid y Universitat Jaume I, 185-187. 